\title{
A preliminary evaluation of unexpected ozone levels measured in Falconara, Italy
}

\author{
G. Latini, R. Cocci Grifoni, G. Passerini \& S. Tascini \\ Dipartimento di Energetica, Università Politecnica delle Marche, Italy
}

\begin{abstract}
Ozone is a secondary pollutant that forms in the atmosphere through complex chemical reactions mainly between Nitrogen Oxides $(N O x)$ and Volatile Organic Compounds ( $V O C$ ); such reactions are triggered by the presence of solar radiation.

In this paper the Ozone formation in the Falconara area, an industrialized area located on the central Adriatic coast of Italy, has been examined during a period of high ozone concentrations that occurred in August 2000 to understand spike phenomena registered in some ozone time series.

The selected data set consists of concentration hourly averages and related elementary values, both provided by the monitoring network of Ancona Province, Italy. We have analysed hourly averages to investigate the long-term and medium-term behaviour of pollutants, while elementary values have been used to study scattering phenomena (low frequency and high frequency fluctuations in concentration levels) registered in some ozone time series.

Spectral analysis has been performed over the air pollutant time series; the focus has been set on photochemical pollutants traced by ozone concentrations, considering potential correlations with chemical precursors, and atmospheric parameters such as solar radiation, wind velocity and air temperature. Analyses conducted led to the hypothesis that the processes that generate ozone in Falconara are more rapid and efficient than in other urban areas, and that ozone production varies significantly over shorter spatial scales than in other urban areas.

Results have yielded possible explanations regarding the origins of the oscillations.
\end{abstract}




\section{Introduction}

Roughly speaking, the Ozone formation is governed by the amount of available Nitrogen Oxides ( $N O x$ ) and Volatile Organic Compounds ( $V O C$ ) but there is no simple relation to describe the connection between the rate of ozone production and the amount of precursors in the atmosphere. In fact, the net photochemical formation of $\mathrm{O}_{3}$ is a non-linear process [1]. $N O x$ and $V O C$ are emitted into the atmosphere from both anthropogenic and biogenic emission sources.

Many different types of $V O C$ compounds are emitted into the atmosphere, each reacting at different rates and having different mechanisms for their reactions. For example, some compounds (e.g. Methane) react and contribute to Ozone formation but they react so slowly that the practical effect on Ozone formation in urban atmospheres is negligible. Others, such as Ethane can be more reactive and may significantly contribute to Ozone formation.

Generally, in an urban area, the Ozone formation is relatively slow and only very special meteorological conditions result in an accumulation of Ozone. Conversely, in an industrialized area the Ozone formation associated with industrial plumes can be more rapid and more efficient than ozone formation in the urban area.

In this paper, a preliminary evaluation of transient high ozone events occurred in 2000 in Falconara area is presented. The monitored data showed an abrupt increase in Ozone concentration by $50-150 \mu \mathrm{g} / \mathrm{m}^{3}$ followed shortly by a nearly abrupt decrease. Spectral analysis of time series related to air pollutants has been used to analyse the data, identify typical and well-known or anomalous periodicities and to disclose their connection with meteorological variables and other factors, as chemical precursors or anthropogenic influences.

Several time series of Ozone elementary data, collected in summer 2000, were characterized by rapid oscillations in concentration levels. This behaviour could be attributed to malfunctions of sampling instruments, for example interference noise introduced by electronic devices or other anomalies of samplers.

We employed the Lomb-Scargle periodogram to estimate the power density spectrum, since such a method is able to deal with unevenly sampled data that are quite common in pollutant time series in which instrumental dropouts or validation problems may lead to incomplete data set with several gaps. A physical process in the time domain can be described in the frequency domain by the Power Spectral Density (PSD) produced through the Fourier transform of the autocorrelation function. The PSD allows detection of hidden periodic components in a noisy time series; in the frequency domain, a periodic component is characterized by a highly energetic peak in the power spectrum of signal.

\section{The Falconara area and the monitoring network}

The Falconara Marittima municipality area, although located on a shoreline, involve an area of about $25 \mathrm{Km}^{2}$ presenting a rather complex orography. It 
extends on an almost flat land on the North and on a hilly area southward. Moreover, the Esino River passes through this territory and flows nearby the town and a very important national route (SS16). Finally, a major highway (A14), a big refinery and an airport are all located in this area.

The region is subject to the presence of breezes that are dominant during the warmest period of the year. Due to the moderate steepness of the Esino valley, valley breezes are very slight although they have a synergic affect with nocturnal land breezes (as well as the mountain breezes for the sea breezes).

The climate in this area is classified as subcoastal. There is an all-year-round sea breeze, of varying intensity influenced by the synoptic circulation, generally from the NW. The sea breeze gives way to a meandering current along the coast, with a component parallel to the coast caused by the synoptic winds. The component perpendicular to the coast, according to the direction, is called coastal breeze or sea breeze, according to the origin of the winds. In the presence of discontinuity, as on the hillsides situated at the entrance of the valley, the sea breeze forces the breeze coming from the valley. This phenomenon is due to a difference in temperature between the land and the air around slopes. The description of the microclimate and landform of this area has been the subject of previous in-depth investigation [2].

Air quality monitoring is carried on through the integrated monitoring network of the Province Authority and a mobile lab is available in the event of severe episodes. At present, there are three monitoring stations within the Falconara municipality area, identified as:

\section{$\checkmark \quad$ "Falconara Scuola" - located nearby the refinery and the sea; \\ $\checkmark$ "Falconara Acquedotto" - close to the refinery but at a higher altitude; \\ $\checkmark$ "Falconara Alta" - located in the historical town centre, several kilometres from the refinery and the see.}

The three monitoring station (Figure 1), along with air quality values, collect meteorological data.

\section{Data analysis}

We analysed data sets of pollutant concentrations and meteorological variables, collected by the monitoring network of Ancona Province, from 1990 to 2000, in the Esino valley. Here, great deal of meteorological phenomena strongly influence moisture and air pollutant concentrations; spectral analysis is particularly useful to study correlations between variables involved in such context.

In the summer of 2000, during July August and September, the alert level (law limit), set at $180 \mu / \mathrm{m}^{3}$ at the Falconara Scuola monitoring station, was exceeded in 109 episodes; 21 episodes were recorded at the Falconara Acquedotto monitoring station whilst no episode at all was registered at Chiaravalle station. This shows a clear and strong difference between the two Falconara stations that are only some 1500 meters apart. 


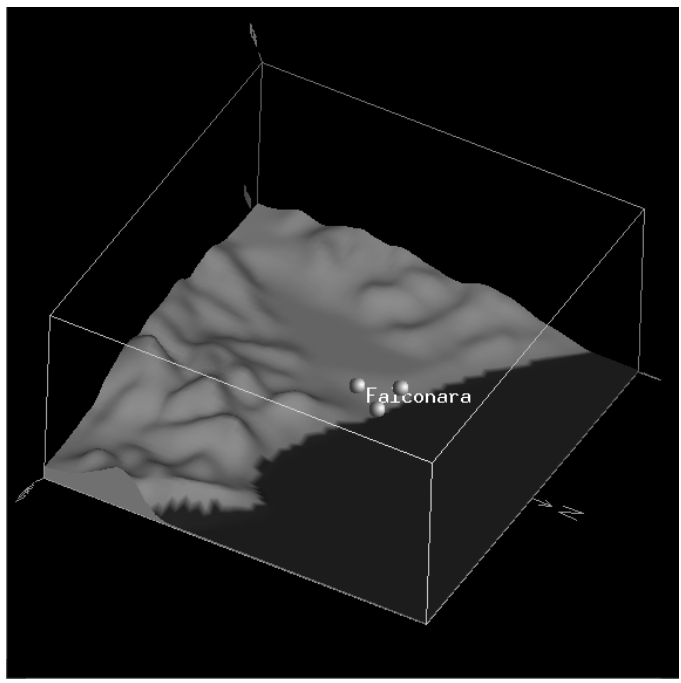

Figure 1: $\quad$ Orography of Esino Valley and Falconara air quality monitoring stations. The dots mark monitoring points.

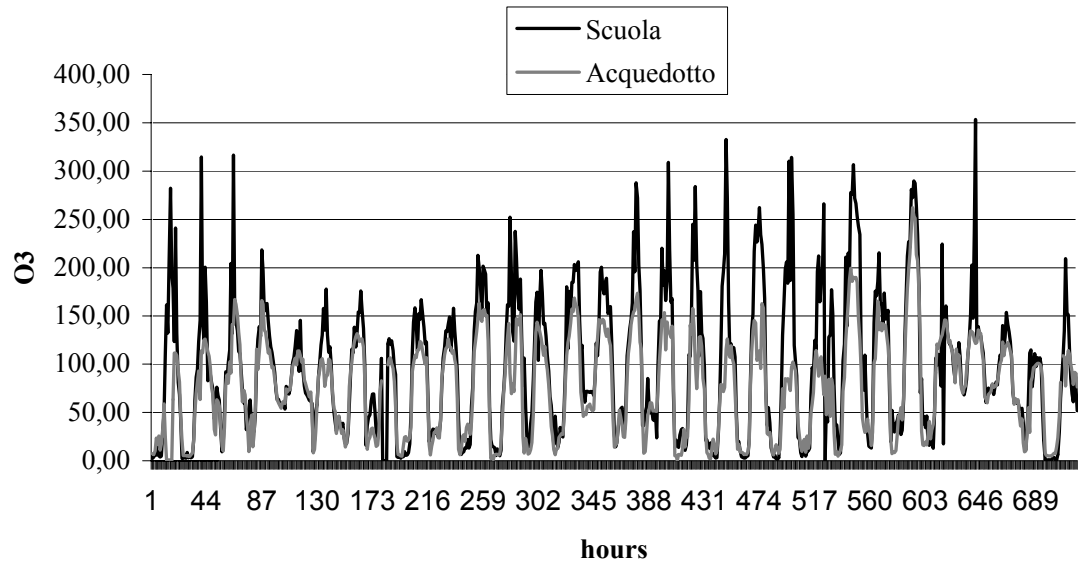

Figure 2: The Ozone behaviour at "Falconara Scuola" and "Falconara Acquedotto" monitoring stations during July August and September 2000 .

Figure 2 shows a comparison of the Ozone levels noted at the two monitoring stations during the month of August 2000. The difference can be explained by analyzing the decidedly non-linear relationship between precursors and Ozone concentration. Reducing emissions of $V O C$ or $N O x$ rarely produce a parallel reduction of Ozone. 
The NOx emission mainly occurs during combustion when Nitrogen and Oxygen combine at high temperatures. By comparing the Nitrogen dioxide trends recorded by the two Falconara monitoring stations during the month of August 2000 (Fig.3), it is possible to note that they have a very similar trends, with only a few sporadic discrepancies.

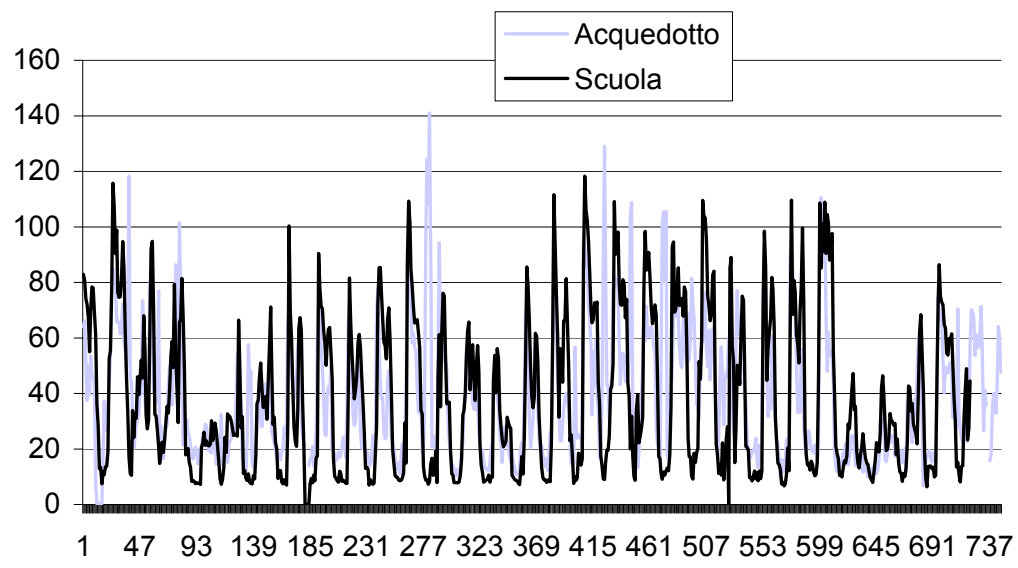

Figure 3: The NOx behaviour at "Falconara Scuola" and "Falconara Acquedotto" monitoring stations during July August and September 2000

A critical point for the prediction of Photochemical Smog formation is the understanding of actual chemical mechanisms involved. Because many of the chemical reactions are not sufficiently understood, the prediction of the impacts of emissions on air quality contains a high degree of uncertainty.

A more difficult problem is assessing the impacts of the oxidation products of the $V O C$. VOC may react to form toxic products, which persist in the environment, or products such as Peroxyacyl Nitrates (PAN) or organic nitrates, which can serve as NOx reservoirs whose subsequent reactions may significantly enhance $\mathrm{O} 3$ formation in downwind, $N O x$-limited environments. Such assessment requires knowledge of the identities and yields of the $V O C$ main reaction products. This is a difficult task as the products are not known or not quantified for many $V O C$. In addition, the products formed when a $V O C$ reacts in the atmosphere will change when $N O x$ levels become so low that radical-radical reactions begin to dominate in the photo-oxidation mechanisms.

It is harder, in this period, to characterize and quantify the $V O C$ emissions. At this point, it is necessary to assess the Lomb periodograms [3-5] for Ozone and Nitrogen dioxide winter datasets (Figures 4 and 5). As a first result we can find that the periodicities of 24-hours and 12-hours are well discovered by the diagrams. These periodicities describe a well-known behaviour of analysed 
pollutants; but spectral analysis may help us to understand if considered data sets contain wrong values, in this way it can support validation procedures.

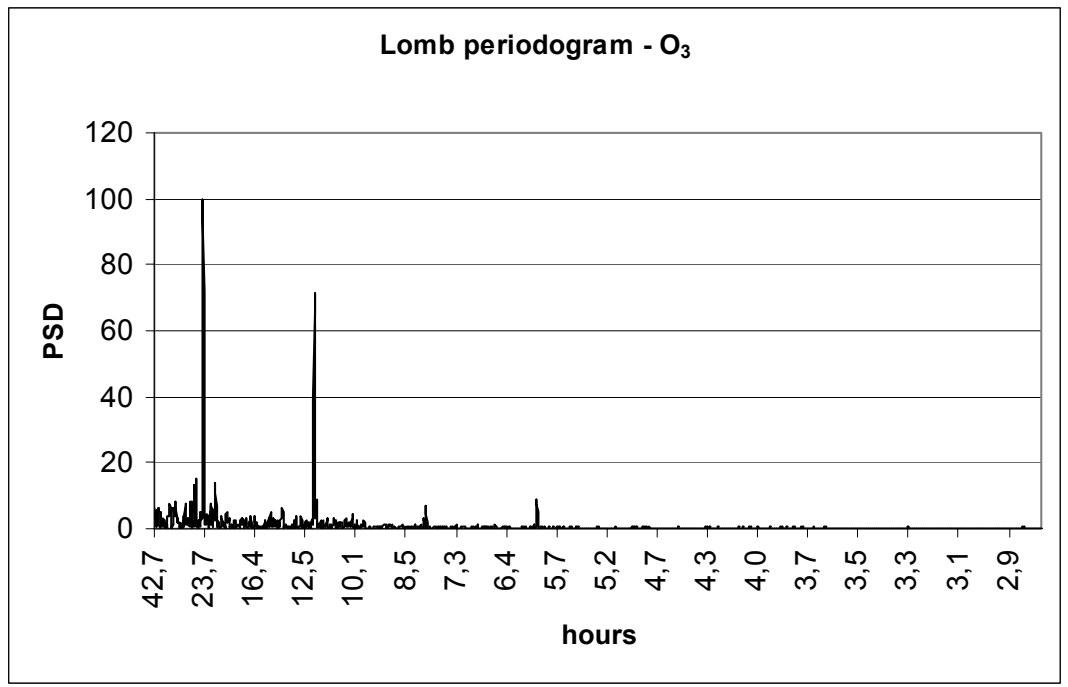

Figure 4: Lomb periodogram of Ozone hourly means collected at "Falconara Scuola" and "Falconara Acquedotto" monitoring stations during July August and September 2000.

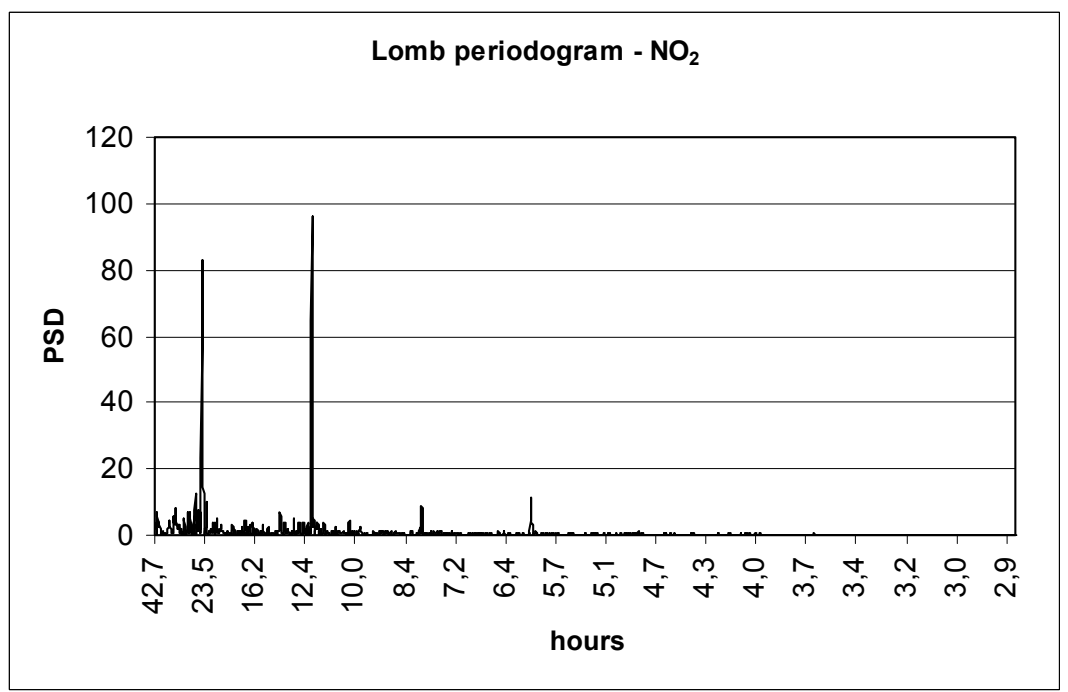

Figure 5: Lomb periodogram of NOx hourly means collected at "Falconara Scuola" and "Falconara Acquedotto" monitoring stations during July August and September 2000. 
For example, in figure 6 we show an anomalous periodogram that reveals a poor quality of acquired data.

After periodogram analysis we computed scattering Ozone data analysis in order to analyse the rapid oscillations in concentration level (see figure 7).

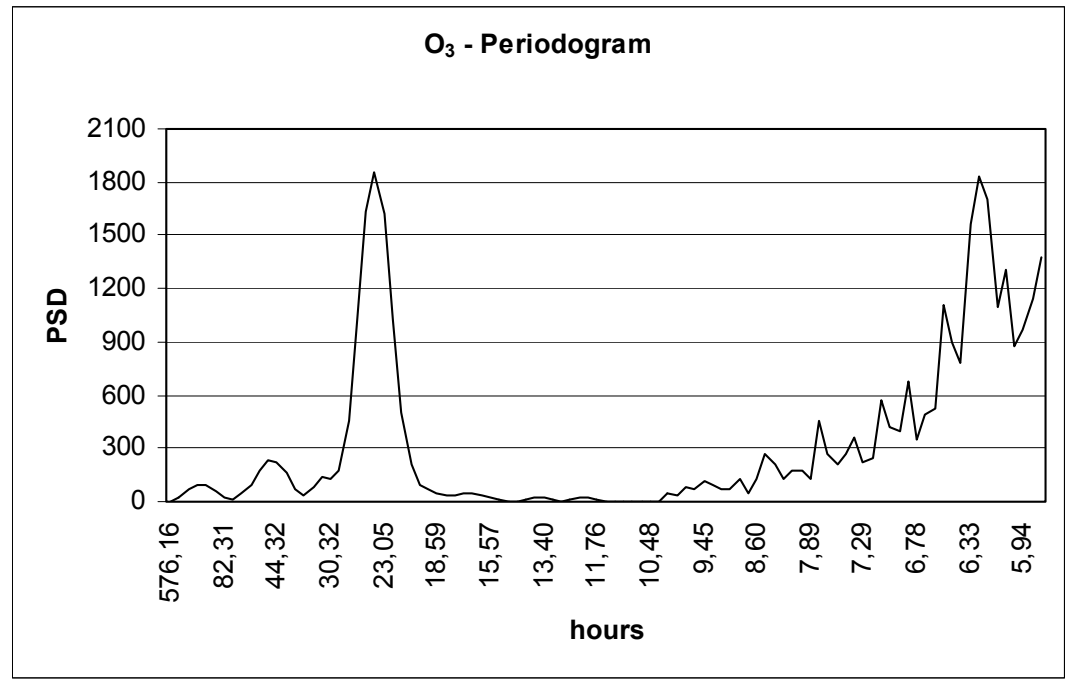

Figure 6: $\quad \mathrm{An}$ anomalous $\mathrm{O}_{3}$ periodogram.

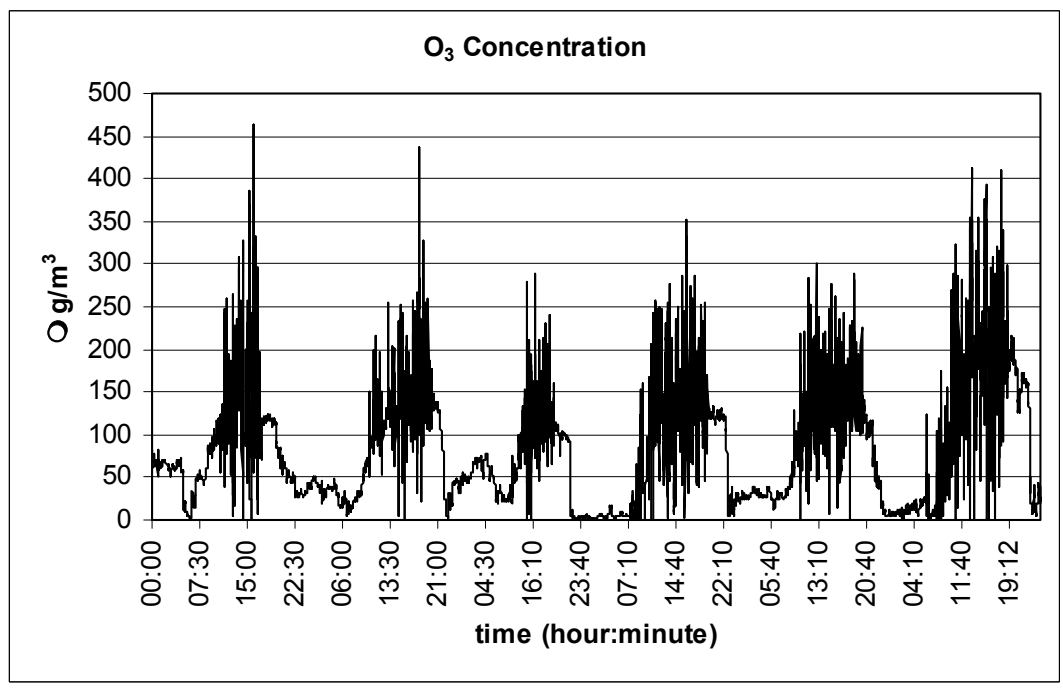

Figure 7: $\quad$ Time series of Ozone concentrations. 
Further data, e.g. from instrument calibrations, might be needed to assess if such conclusion is true. However, by means of PSD we may evaluate, at least, if high frequency periodic signals are superimposed to concentration data.

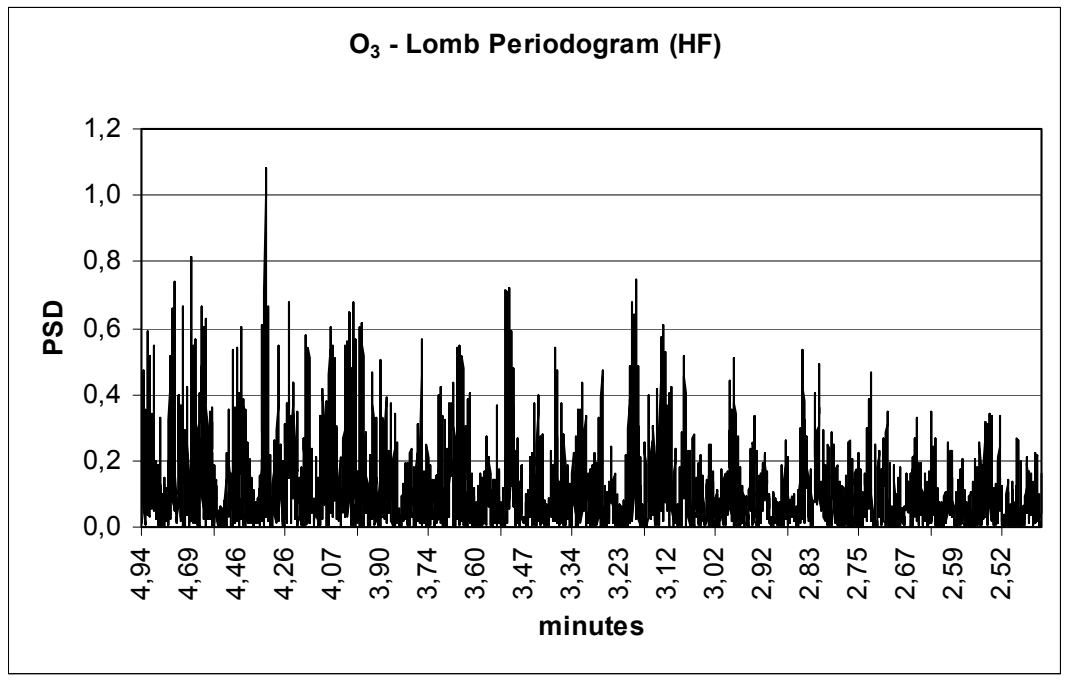

Figure 8: Lomb periodogram of Ozone elementary data collected at "Falconara Scuola" and "Falconara Acquedotto" monitoring stations during July August and September 2000.

The periodogram of Figure 8 do not show any statistically significant peak at high frequencies. The spectrum in Figure 8 is similar to a white noise spectrum, where all frequencies have the same statistical significance.

It is important to remember that consideration must also be given to the prevailing weather conditions, the effect of the sea breezes and the evolution of the mixing layer. After sunrise, the photochemical formation from precursors starts and gradually grows as the amount of sunlight increases. Then, the mixing of air from layers aloft and from the free troposphere also plays a role. Photochemical reactions that are sustained by fresh emissions of precursors, that have mostly anthropogenic origins, lead to the formation of new Ozone. What is more, as the day evolves, the temperature rises and with it, the emission of Volatile Organic Compounds of biogenic origin. These compounds react effectively with the Nitroxides and form further significant quantities of new Ozone. The progressive increase of the mixing layer can capture air masses containing significant levels of Ozone that have been stored from the previous day.

\section{Conclusions}

In this paper a preliminary evaluation of rapid events of Ozone formation have been presented. 
As first step, the frequency analysis has been successfully adopted in data validation procedures. Such validation was helpful in assessing whether a dataset contains anomalous values and in explaining strange data trends by means of coherence spectra between pollutant values and meteorological and/or chemical precursors.

Previous eassessment of pollutant behaviour, surface wind patterns, and some meteorological parameters $[6,7]$ suggested that high Ozone concentrations occur during the days with intense solar radiation, light winds, in the presence of a typical coastal wind circulation (sea-land breeze). Such preliminary results call for further studies, with the aim of setting up an adequate air-quality assessment.

In order to improve results for ozone we suggest considering an accurate examination of surface wind patterns and other ozone precursors. More systematic studies will be needed (measurements and modelling) in order to characterize and quantify the $V O C$ emissions.

\section{Acknowledgement}

This research has been supported by the Ministero dell'Istruzione Università e Ricerca.

\section{References}

[1] Sillman, S.: 1999, 'The Relationship between Ozone, NOx and Hydrocarbons in Urban and Polluted Rural Environments', Atmos. Environ. 33, 1821-1845.

[2] Latini, G., Cocci Grifoni, R. and Passerini G.: 2002, "Influence of meteorological parameters on urban and suburban air pollution", in C.A. Brebbia and G. Latini (eds.), Air Pollution IX, WIT Press, Southampton (GB), pp. 753-762.

[3] Lomb N R, 1976, Least-squares frequency analysis of unequally spaced data, Astrophysics and Space Science, vol. 39, pp. 447-462.

[4] Scargle J D, 1982, Studies in astronomical time series analysis II. Statistical aspects of spectral analysis of unevenly spaced data. Astrophysical Journal, vol. 263, pp. 835-853.

[5] Press W H, Rybicki G B, 1989, Fast algorithm for spectral analysis of unevenly sampled data, Astrophysical Journal, vol. 338, pp. 227-280.

[6] Cocci Grifoni R., Magnaterra L., Passerini G., Tascini S., Importance of local meteorology in coastal ozone dynamics: a case study, in Air Pollution XI, WIT Press, Southampton (GB), pp. 95-104, 2003.

[7] Cocci Grifoni R., Passerini G., Tascini S., An assessment of the sea/valley breeze and its impact on ozone behaviour, in Coastal Environment V, WIT Press, Southampton (GB), pp. 257-267, 2004. 